\title{
Ajudar o próximo ou ser recompensado? Comportamento distributivo infantil em situações envolvendo mérito e altruísmo
}

\author{
Leonardo Rodrigues Sampaio \\ Universidade Federal do Vale do São Francisco, PE, Brasil \\ Cleonice Pereira dos Santos Camino \\ Universidade Federal da Paraíba, PB, Brasil
}

\begin{abstract}
Resumo
Crianças usam diferentes princípios para partilhar bens, a depender de suas idades e das informações disponíveis no contexto de distribuição, com uma tendência ao igualitarismo e altruísmo maiores à medida que suas idades avançam. No presente estudo o comportamento distributivo infantil foi avaliado em uma situação experimental na qual questões envolvendo o mérito pessoal e o cuidado com o próximo eram manipuladas. Foi utilizado um jogo computacional no qual a criança nomeava animais e podia decidir como a recompensa deveria ser dividida entre ela e seu adversário. Foi observado que as crianças entre 11 e 12 anos e aquelas que receberam informações sobre como o seu adversário de jogo ficaria após perder a partida tenderam a ser mais generosas. Ademais, crianças com maiores níveis de empatia foram menos egoístas. Esses resultados são discutidos a partir da teoria de Martin Hoffman e de achados empíricos recentes no campo da justiça distributiva.
\end{abstract}

Palavras-chave: Partilha; Crianças; Jogo; Mérito; Altruísmo.

\section{To help your neighbor or being rewarded? Children's sharing behavior in situations involving merit and altruism}

\begin{abstract}
Children use different principles to share goods, depending on their ages and the information available in the context of distribution, with a increasing preferency for egalitarianism and altruism as they grow up. In the current study children's distributive behavior was evaluated through an experimental situation in which issues involving personal merit and care were manipulated. A computer game during which children named animals and could decide how the reward should be shared was used. It was observed that children aged 11 to 12 years and those who received information about how their opponents would stay after losing the game tended to be more generous. In addition, more empathic children were less selfish. These results are discussed from the perspective of Martin Hoffman's theory, and from recent empirical findings in the field of distributive justice.
\end{abstract}

Keywords: Sharing; Children; Game; Merit; Altruism.

\section{Ajudar el próximo o ser recompensado? Comportamiento distributivo infantil en situaciones envolvendo mérito y altruísmo}

\section{Resumen}

Los niños utilizan diferentes principios para compartir, dependiendo de su edad y de la información disponible en el contexto de distribución, con una tendencia a la igualdad y el altruismo mayor a medida que envejecen. En el presente estudio se evaluó el comportamiento distributivo de los niños en una situación experimental en la que se manipularon cuestiones relacionadas con el mérito personal y la cuidado al outro. Fue utilizado un juego de computadora durante el cual los niños nombraron animales y pudieron decidir cómo se debía compartir la recompensa. Se observó que los niños entre 11 y 12 años y los que habían recibido información sobre como su oponente se sintió después de perder el juego tendía a ser más generosos. Además, los niños con niveles más altos de empatía eran menos egoísta. Estos resultados se discuten desde la teoría de Martin Hoffman y estudios recientes en el campo de la justicia distributiva.

Palabras clave: Division; Niños; Juego; Mérito; Altruismo. 
Os julgamentos infantis em situações distributivas foram primeiramente investigados por Piaget, em seu trabalho sobre o juízo moral infantil (Piaget, 1932/1994). Utilizando o método clínico e histórias hipotéticas, Piaget observou modificações nos raciocínios distributivos relacionados a avanços na idade: crianças pequenas (cerca de 6 anos) achavam que a maneira mais justa de dividir as coisas era seguir unilateralmente instruções fornecidas pelos adultos; por volta dos 8 anos as crianças começavam a usar um princípio de igualdade absoluta e a julgar que a maneira mais justa de compartilhar as coisas era atribuir exatamente o mesmo montante a todos os envolvidos; e, finalmente, por volta dos 11 anos, as crianças tendiam a substituir esse igualitarismo por um raciocínio ligado à equidade. Assim, elas julgavam que em situações de partilha o mais justo era considerar as diferenças pessoais (por exemplo, desvantagens, idade, necessidade, etc.) e pesar essas características durante a alocação dos bens disponíveis.

Evidências empíricas corroboram o modelo teórico piagetiano de desenvolvimento da justiça distributiva (Sampaio, Camino, \& Roazzi, 2007; Wong \& Nunes, 2003). No entanto, alguns pesquisadores têm criticado a tese piagetiana sobre moralidade, principalmente por dois motivos: primeiro, porque esse autor teria subestimado a influência de aspectos afetivos sobre o comportamento moral (Hoffman, 2000; Sampaio, Camino, \& Roazzi, 2009); em segundo lugar, porque estudos empíricos demonstram que as pessoas não se comportam de acordo com os princípios morais que elas mesmas defendem. Ou seja, elas preferem adotar comportamentos distributivos que promovem o autobenefício, mesmo após terem defendido verbalmente a necessidade de utilização de princípios baseados na cooperação ou pró-sociabilidade (Batson et al., 1999).

Recentemente, Smith, Blake e Harris (2013) observaram que crianças também demonstravam incoerência entre o que fazem e o que alegam ser mais justo em situações distributivas. Usando adesivos como bens e um jogo ditatorial como situação distributiva, esses autores observaram que as crianças defendiam a aplicação de um regra de igualdade por seus parceiros de jogo, ao mesmo tempo em que ficavam com quase todos (senão todos) os adesivos disponibilizados. Porém, a inconsistência entre os julgamento e comportamento distributivo diminuía radicalmente entre os cinco e oito anos de idades, com as crianças mais velhas demonstrando uma forte preferência por divisões igualitárias.

Essa tendência de maior adesão à norma da igualdade por crianças mais velhas, também foi observada por Fehr, Bernhard e Rockenbache (2008), durante um estudo no qual os participantes tinham a oportunidade de escolher algumas opções de alocação de bens entre si e outros jogadores (que eram, na verdade, personagens fictícios). Nos resultados, os autores constataram que os participantes de 3 a 4 anos eram menos dispostos a compartilhar os seus bens e que as crianças de 7 a 8 anos, preferiam distribuições que se aproximavam mais da igualdade, demonstrando-se resistentes a distribuições não igualitárias.

Utilizando um procedimento experimental similar, Blake e McAuliffe (2011) observaram que ate os 7 anos de idade as crianças não resistiam a aceitar distribuições vantajosas para si, ou seja, aquelas nas quais elas ganhariam quatro doces, enquanto uma outra criança receberia apenas um. Porém, a partir dos 8 anos de idade as crianças passavam a não aceitar divisões nas quais ganhavam mais (divisões vantajosas) ou divisões nas quais elas ganhavam menos doces (divisões desvantajosas), preferindo, majoritariamente, divisões igualitárias, ainda que isso resultasse em um sacrifício para elas mesmas. Outros estudos demonstram que crianças entre seis e oito anos de idade tendem a corrigir desigualdades distributivas, sendo capazes de levar em conta não apenas a quantidade de recursos alocados, mas também o valor dos bens envolvidos, o que sugeriria a presença de uma noção de justiça distributiva relativamente complexa já nesta idade (Shaw \& Olson, 2013).

Um importante aspecto a ser destacado nessas pesquisas é o fato das crianças sempre realizarem as suas escolhas na presença dos pais e de outras pessoas, ou seja, em um contexto público. Outros estudos corroboram a tese de que o altruísmo tende a se tornar mais forte entre os cinco e oito anos de idade, mas também demonstram que o fato da tomada de decisão distributiva ocorrer em contextos públicos ou privados influencia fortemente o comportamento distributivo infantil (Blake \& Rand, 2010; Posid, Fasio, \& Cordes, 2015). Por exemplo, Sampaio e Pires (2015) observaram que o comportamento egoísta pode ocorrer mesmo entre crianças mais velhas, desde que elas tenham a oportunidade de fazer a divisão dos bens em um contexto privado, ou seja, quando acreditam que ninguém saberá como a divisão foi feita.

Este resultado aponta para a influência que a desejabilidade social pode ter sobre o comportamento distributivo infantil e vai na mesma direção de pesquisas com adultos, nas quais se buscou aumentar o comportamento altruísta por meio de manipução das pistas situacionais disponíveis no contexto de distribuição, relacionadas à auto-imagem (Batson et al., 1999), tomada de perspectiva (Batson et al, 2003) e cuidado com o próximo (Batson et al, 1995). 
De uma maneira geral, esses estudos sugerem que a frequência de comportamentos distributivos altruístas pode ser aumentada se sentimentos empáticos de cuidado para com o outro forem estimulados, por meio do fornecimento de informações relacionadas aos possíveis beneficiários da distribuição, o que está de acordo com o proposto por Hoffman (2000), em sua teoria sobre a relação entre justiça e empatia.

Todavia, este efeito da empatia sobre o comportamento distributivo foi observado em sujeitos adultos e adolescentes apenas, por isso não se sabe ao certo se manipulações experimentais de mesma mesma natureza provocariam efeitos semelhantes em crianças. Ademais, na maioria dos estudos sobre justiça distributiva com crianças, os participantes estavam na perspectiva de um observador neutro, ou seja, as consequências da distribuição nunca os afetavam diretamente, pois ocorriam em cenários hipotéticos. Assim, pode-se questionar: quando as crianças estiverem na perspectiva de alguém que será afetado pela distribuição, pistas situacionais sobre outros possíveis beneficiários da distribuição poderão influenciar seu comportamento distributivo?

Destaca-se ainda que, apesar de estudos anteriores terem utilizado situações nas quais questões sobre mérito e o cuidado com o outro foram apresentadas, nenhum deles averiguou se as modificações na justiça distributiva relacionadas à idade permaneceriam quando a aplicação de princípios baseados no mérito pessoal pudessem beneficiar o próprio agente da distribuição. Neste sentido, é importante questionar: as crianças procurarão beneficiar o outro, quando um princípio baseado no desempenho pessoal as favorecer? Caso as crianças procurem se autobeneficiar, essa tendência continuará a ocorrer quando elas souberem que a distribuição pode causar algum tipo de sofrimento psicológico à outra criança envolvida na situação distributiva?

Para responder os questionamentos levantados, elaborou-se uma situação experimental na qual as informações sobre mérito e cuidado com o outro foram manipuladas, observando-se se essas manipulações influenciariam a maneira como as crianças distribuíam bens em um contexto de jogo. Além disso, foi avaliado se as crianças estariam conscientes das consequências de suas decisões distributivas para um beneficiário em potencial e se isso interferiria na maneira como elas distribuiriam os bens disponíveis.

\section{Método}

\section{Participantes}

163 meninos $(49,7 \%)$ e meninas com idades variando entre cinco e doze anos $(\mathrm{M}=8,48 ; \mathrm{dp}=2,28)$, matriculados em creches e escolas públicas e privadas da cidade de Petrolina (PE) participaram do estudo. Para fins de análise, as crianças foram categorizadas em quatro grupos etários: 5 a 6 anos $(n=41 ; 48,8 \%$ meninos; $\mathrm{M}=5,50 ; \mathrm{dp}=0,50), 7$ a 8 anos $(\mathrm{n}=41$; $51,2 \%$ meninos; $\mathrm{M}=7,51 ; \mathrm{dp}=0,50), 9$ a 10 anos $(\mathrm{n}=42 ; 47,6 \%$ meninos; $\mathrm{M}=9,52 ; \mathrm{dp}=0,50)$ e 11 a 12 $\operatorname{anos}(\mathrm{n}=39 ; 51,3 \%$ meninos; $\mathrm{M}=11,51 ; \mathrm{dp}=0,50)$. As crianças pertenciam a famílias com diferentes níveis socioeconômicos e eram, em sua maioria, brancas e pardas.

\section{Instrumentos}

O principal instrumento utilizado nesta pesquisa foi um jogo computadorizado, chamado de "Sabichão", constituído por perguntas sobre o nome de animais. Cada rodada do jogo "Sabichão" consistia na exibição da imagem de um animal, seguido pela pergunta "Qual animal é o (ex: papagaio)?" e a apresentação de duas imagens como opções de respostas na tela. Foram expostas imagens de animais não familiares aos participantes (ex: peixe bolha, ornitorinco, equidna), buscando-se evitar que as crianças conseguissem contabilizar suas respostas corretas (Figura 1). Uma partida completa do jogo durava dez rodadas e a tarefa dos participantes era simplesmente usar o mouse do computador para clicar sobre a imagem do animal correspondente ao nome enunciado.

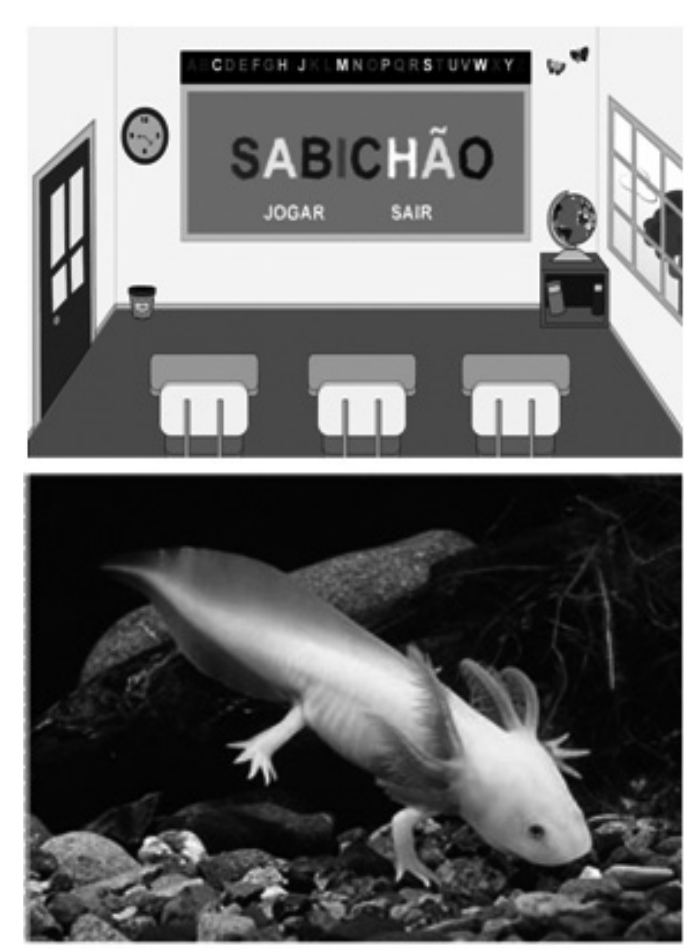

Figura 1. Tela de abertura do "Sabichão" e exemplo de imagem de animal não familiar. 
Cartões de papel de cor bege foram entregues após a partida e podiam ser trocados por cartelas de adesivos pelo ganhador do jogo, após a finalização da partida. Envelopes de papel vermelho com a foto do outro jogador (fictício) serviram para que cada criança indicasse como os cartões deveriam ser distribuídos entre ela e o seu adversário no jogo, quando a partida terminasse. Folhas de papel ofício com imagens coloridas de rostos (smile-faces) com diferentes expressões (neutra, alegre, com raiva ou triste) foram usadas para que os participantes indicassem como eles imaginavam que seu adversário se sentiria ao receber o envelope deixado para eles após o término da partida.

O nível de empatia das crianças foi mensurado através da Escala de Bryant (Bryant, 1982), em sua versão traduzida e adaptada para uso no Brasil por Ribeiro, Koller e Camino (2002), que foi lida para os participantes, para facilitar a compreensão do instrumento. Por fim, foi utilizado um pequeno questionário para levantamento de dados sociodemográficos, que foi enviado aos pais junto com o Termo de Consentimento Livre e Esclarecido (TCLE).

\section{Procedimentos}

A Escala de Empatia de Bryant (1982) foi administrada em primeiro lugar e após isso o participante foi convidado a jogar o "Sabichão" com outra criança (adversário), através de um computador disponível na sala. O "Sabichão" consistia num jogo de perguntas e respostas durante o qual foram mostradas figuras de animais e questionado qual imagem correspondia ao animal nomeado.

$\mathrm{Na}$ tela inicial do Sabichão, a criança deveria se posiconar e tirar uma foto de si mesma com a câmera do computador, para que ela fosse exibida ao lado da foto de seu (sua) adversário (a), que era, na verdade fictício e cuja foto foi obtida de um portal de pesquisas da internet. Cada participante sempre tinha como adversário de jogo uma criança do seu mesmo sexo e faixa etária.

Durante a partida eram apresentadas perguntas sobre um determinado animal e oferecidas duas opções de imagens para que as crianças indicassem qual delas correspondia ao animal cujo nome havia sido enunciado. Ao fim de dez rodadas, a tela do computador indicava a quantidade de acertos totais do jogador e de seu adversário, de acordo com a condição experimental do estudo. Após repetir verbalmente o total de acertos exibido na tela do computador, o pesquisador dizia a seguinte frase: "Muito bem. Já sabemos que você acertou (seis ou nove) respostas. Agora, irei ligar para meu colega que está em outra sala, para que possamos saber quantas respostas o seu parceiro de jogo acertou". Após alguns minutos, o pesquisador dizia ao participante que seu parceiro de jogo havia acertado apenas (cinco ou duas) respostas.

Foram manipulados dois tipos de informações (resposta afetiva do adversário do jogo e desempenho do participante na tarefa), constituindo um delineamento fatorial do tipo 2 (condição neutra, ou emocional) $\times 2$ (vitória por 9 a 2 pontos, ou por 6 a 5 pontos), com quatro condições experimentais, para as quais os participantes foram designados aleatoriamente. Desta forma, nas condições chamadas de "neutras" não foi fornecida nenhuma informação adicional sobre o outro jogador, enquanto que nas condições chamadas de "emocionais" o pesquisador dizia o seguinte, após o término da partida: “....meu colega que está na outra sala acabou de me dizer que seu parceiro de jogo ficou realmente muito triste quando soube que havia perdido o jogo e que poderia ficar sem ganhar nada por causa disso".

Depois de informar os resultados finais do Sabichão, o pesquisador entregou um envelope vermelho e quatro cartões coloridos para cada criança e disse que ela havia ganho o direito de decidir como os prêmios seriam divididos. Cada cartão colorido poderia ser trocado por uma cartela de adesivos de sua preferência. Além disso, o pesquisador dizia a seguinte frase: "Você não é obrigado a dar nenhum cartão para a outra criança que estava jogando com você, mas se você quiser fazer isso, basta colocar a quantidade de cartões que você quiser dar para o seu parceiro dentro desse envelope vermelho, que nós iremos entregar para ele depois que você for embora. Porém, como eu disse antes, você não é obrigado a deixar nenhum cartão para ele(a) se não quiser". Na sequencia, o pesquisador saia da sala por alguns instantes e dizia que o participante poderia tomar sua decisão e deixar o envelope vermelho sobre a mesa, pois ele seria recolhido posteriormente.

Quando o participante terminava sua distribuição, o pesquisador voltava a sala e mostrava figuras coloridas de faces com diferentes expressões emocionais (neutra, alegre, com raiva e triste) e solicitava que o participante indicasse qual das faces representava como o seu parceiro se sentiria, quando recebesse o envelope vermelho com os cartões coloridos que ele havia deixado.

Finalizados os procedimentos de coleta de dados o pesquisador dizia à criança que na verdade ela não estava jogando contra ninguém e que ele poderia ficar com os cartões deixados no envelope vermelho na outra sala, se assim desejasse. Por fim, o pesquisador 
se colocava à disposição para responder quaisquer questões que as crianças ou seus pais desejassem fazer. As crianças foram entrevistadas individualmente, em suas escolas, em local previamente designado pela Coordenação Pedagógica.

Os procedimentos adotados nesta pesquisa seguiram as orientações previstas na Resolução 466/12 do Conselho Nacional de Saúde (BRASIL, 2012) e na Resolução 016/2000 do Conselho Federal de Psicologia (CFP, 2000), que tratam da Ética na Pesquisa com Seres Humanos. Antes de sua execução, o projeto foi aprovado pelo Comitê de Ética em Pesquisas com Seres Humanos da Univasf (protocolo no 0011/200813 CEDEP/UNIVASF). As crianças só foram entrevistadas após seus pais ou responsáveis terem autorizado sua participação na pesquisa, por meio da assinatura de um Termo de Consentimento Livre e Esclarecido. Além disso, as crianças assinaram um Termo de Assentimento adequado a cada idade e puderam manifestar verbalmente seu interesse em continuar ou se retirar da sessão experimental a qualquer momento.

\section{Resultados}

De maneira geral, as crianças tenderam a doar $1,23(\mathrm{dp}=0,85)$ cartelas de adesivos para o adversário do jogo, valor este que difere significativamente de um padrão de distribuição igualitário (dois adesivos para cada um que participou do Sabichão), conforme o resultado do teste $t(t=11,53 ; p<0,001)$.

Buscando avaliar a possível influência do sexo, idade e condição experimental das crianças sobre sua decisão distributiva, utilizou-se uma ANOVA (one-way), associada ao Post Hoc Test de Tukey, considerando como critério de significância o valor limite de 0,05 . Os resultados desta análise indicaram efeitos significativos do sexo $[F(1,163)=5,07 ; p=0,02$; $\left.\eta_{\mathrm{p}}{ }^{2}=0,03\right]$ e da idade $[\mathrm{F}(3,163)=6,51 ; \mathrm{p}<0,001$; $\left.\eta_{\mathrm{p}}{ }^{2}=0,13\right]$ dos participantes, além de uma interação significativa entre condição experimental e idade $\left[\mathrm{F}(9,163)=3,09 ; \mathrm{p}=0,002 ; \eta_{\mathrm{p}}{ }^{2}=0,17\right]$. De maneira geral, os meninos $(\mathrm{M}=1,38 ; \mathrm{dp}=0,86)$ tenderam a ser um pouco mais generosos para com o adversário de jogo do que as meninas $(M=1,11 ; d p=0,86)$, o que vai de encontro ao que é observado na literatura que, em geral, sugere que as mulheres tendem a ser mais igualitárias do quê adultos do sexo masculino, ou ainda de que não haveria diferenças significativas relacionadas ao sexo, pelo menos até o início da adolescência (Smith, Blake, \& Harris, 2013).

No que se refere à idade, houve uma tendência de a quantidade de adesivos doados ir aumentando à medida que a idade avançava (5 a 6 anos, $\mathrm{M}=0,88$; $\mathrm{dp}=0,92 ; 7$ a 8 anos, $\mathrm{M}=1,17 ; \mathrm{dp}=0,86 ; 9$ a 10 anos, $\mathrm{M}=1,21 ; \mathrm{dp}=0,64$ e 11 a 12 anos, $\mathrm{M}=1,67 ; \mathrm{dp}=0,80$ ). Conforme demonstrou o teste de Tukey, as crianças entre 11 e 12 anos doaram, de forma geral, quantidade média superior de adesivos, diferindo de todas as outras faixas etárias $(p<0,05)$, enquanto os três outros grupos etários não diferiram entre si.

Quanto à interação entre idade e condição experimental, follow-up análises demonstraram que enquanto as crianças de 8 a 12 anos não variaram significativamente a quantidade média de adesivos doados em função da condição experimental, as de 5 a $6\left[\mathrm{~F}(3,41)=4,60 ; \mathrm{p}=0,008 ; \eta_{\mathrm{p}}{ }^{2}=0,27\right]$ e 7 a 8 anos $\left[\mathrm{F}(3,41)=2,73 ; \mathrm{p}=0,05 ; \eta_{\mathrm{p}}{ }^{2}=0,18\right]$ tenderam a doar quantidades significativamente diferentes, em função da condição que participaram (Figura 2).

Para aprofundar as análises a respeito do comportamento distributivo dos participantes, as crianças foram categorizadas em dois grupos: egoístas (quando o participante não doava nenhum adesivo) ou altruístas (quando a criança doava pelo menos um adesivo). $\mathrm{O}$ teste do Qui-quadrado demonstrou que o maior percentual de crianças egoístas foi encontrado no grupo etário de cinco a seis anos $\left(\chi^{2}=14,71 ; g .1 .=3 ; p=0,02\right)$ e no grupo de crianças que participou da condição $9 \times 2$, neutra $\left(\chi^{2}=7,36 ;\right.$ g.1. $\left.=3 ; p=0,06\right)$ (Figura 3$)$.

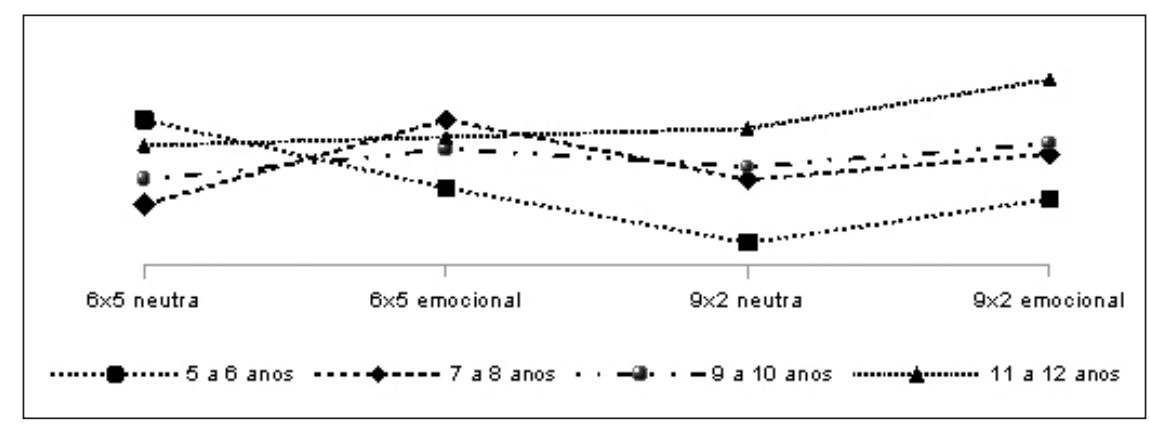

Figura 2. Média de adesivos doados em função da idade e condição experimental. 
Além disso, o menor percentual de crianças egoístas foi observado entre aquelas que participaram da condição $6 \times 5$, emocional e entre as mais velhas ( 11 a 12 anos). Não houve diferença significativa no percentual de crianças egoístas relacionadas ao sexo.

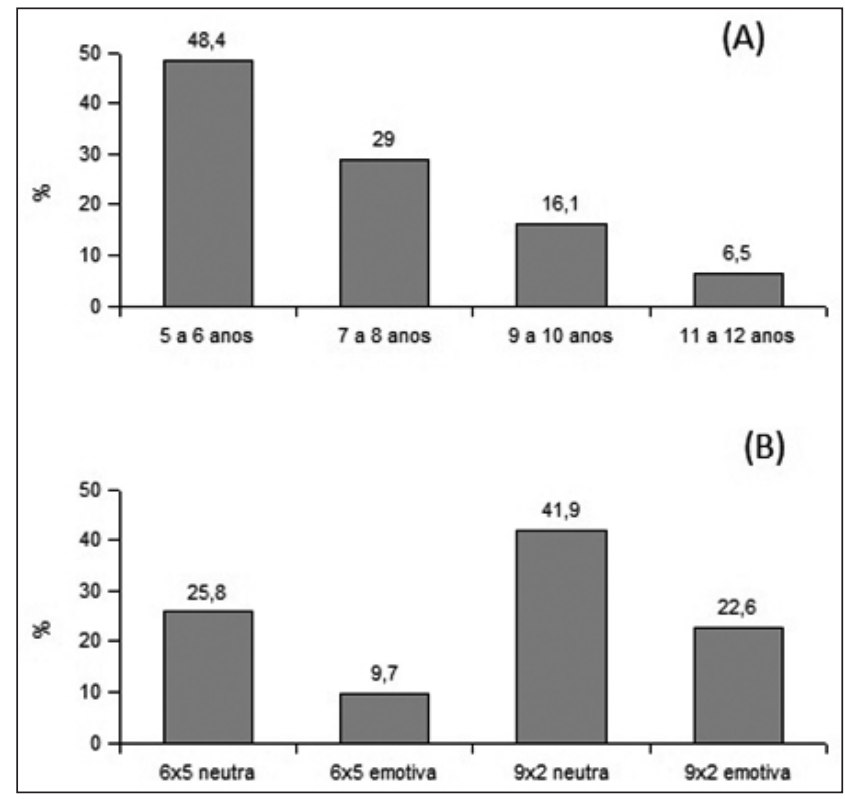

Figura 3. Percentual de crianças egoístas em função da idade (A) e condição experimental (B).

Apesar de os resultados da ANOVA não terem sido significativos para a comparação entre as quantidades médias doadas em função de cada condição experimental isoladamente, observou-se um padrão de resultados que sugere uma maior disposição para as crianças doarem um pouco mais de adesivos nas duas condições emotivas: condição $6 \times 5$, neutra: $M=1,2$ $(\mathrm{dp}=0,12)$; condição $6 \times 5$, emotiva: $\mathrm{M} 1,36(\mathrm{dp}=0,11)$; condição 9x2, neutra: $M=1,0(d p=0,11)$; condição $9 \times 2$, emotiva: $M=1,41(d p=0,12)$. Para avaliar de forma mais específica este padrão foram constituídas uma medida correspondente à soma das quantidades médias doadas nas duas condições emotivas e outra medida que corresponde à soma das quantidades médias doadas nas duas condições neutras. Os resultados das análises demonstraram que nas condições emotivas as crianças doaram em média 1,39 adesivos $($ d.p. $=0,83)$, enquanto que nas condições neutras a doação média foi de 1,07 adesivos (d.p. $=0,84)$, com o Teste $t$ indicando que estas duas médias eram significativamente diferentes entre si $(t=-2,43 ; p=0,01)$.

\section{Comportamento distributivo e empatia}

Análises de variância demonstraram que as meninas $(M=14,67 ; d p=2,61)$ avaliaram-se como sendo mais empáticas que os meninos $(M=13,70$; $\mathrm{dp}=3,17) \quad\left[\mathrm{F}(1,163)=6,16 ; \quad p=0,01 ; \quad \eta_{\mathrm{p}}{ }^{2}=0,40\right]$. Além disso, indicaram que o índice de empatia variou significativamente entre as faixas etárias $\left[\mathrm{F}(3,163)=6,17 ; \quad p=0,01 ; \quad \eta_{\mathrm{p}}^{2}=0,11\right], \quad$ com os participantes mais novos tendendo a atingir as menores pontuações $(\mathrm{M}=11,92 ; \mathrm{dp}=2,89)$ na escala de Bryant (1982) e se diferenciando das demais faixas etárias (Post-hoc Test de Tukey com $p<0,05$ para todas as comparações). Não se verificaram diferenças significativas entre crianças de 7 a 8 anos $(M=15,61$; $\mathrm{dp}=2,40), 9$ a $10(\mathrm{M}=13,95 ; \mathrm{dp}=2,82)$ e de 11 a 12 anos $(M=15,28 ; d p=2,93)$, no que se refere aos níveis de empatia.

Quanto às relações entre a quantidade de adesivos doados e a empatia, o teste de Pearson indicou a existência de uma correlação positiva e significativa entre essas duas variáveis $(\mathrm{r}=0,18 ; p=0,02)$. Ademais, uma análise de variância univariada apontou que as crianças consideradas altruístas $(\mathrm{M}=14,50 ; \mathrm{dp}=2,97)$ obtiveram média de pontuação mais elevada na escala de Bryant do quê as crianças categorizadas como egoístas $(\mathrm{M}=12,83 ; \mathrm{dp}=2,35) \quad[\mathrm{F}(1,161)=8,42$; $\left.p=0,04 ; \eta_{\mathrm{p}}^{2}=0,24\right]$.

Por fim, o teste de correlação de Pearson indicou a existência de uma correlação direta e significativa $(\mathrm{r}=0,58 ; p<0,001)$ entre a quantidade de adesivos doados pelos participantes e o grau de satisfação que eles inferiam que a outra criança estaria sentindo. Este resultado indica que os participantes tinham uma clara consciência sobre como o beneficiário em potencial (adversário do jogo) reagiria ao receber uma quantidade maior ou menor de adesivos, prevendo, corretamente, que quanto mais cartelas de adesivos fossem deixadas no envelope, mais a outra criança ficaria feliz, e vice-versa.

\section{Discussão}

De maneira geral, apesar das crianças terem se disponibilizado a ajudar o seu adversário no jogo, esta motivação não as obrigou a utilizar uma regra de igualdade na distribuição dos adesivos, o que pode ser explicado pelo fato de o próprio participante ser o vencedor do jogo. Neste sentido, as crianças teriam usado uma regra de equidade baseada no mérito (o que a beneficiaria), para decidir que modelo distributivo deveria ser adotado para resolução da situação, o que contraria os estudos anteriores que sugerem a existência de uma tendência a rejeitar distribuições não igualitárias por volta dos oito anos de idade (Blake \& McAuliffe, 2011; Fehr, Bernhard, \& Rockenbach, 2008). 
Por outro lado, os resultados demonstram ainda que as pistas situacionais disponibilizadas durante o experimento influenciaram significativamente a decisão das crianças doarem ou não os adesivos que haviam ganho durante a partida do "Sabichão". Mais especificamente, constatou-se que a idade e, consequentemente, avanços nas capacidades cognitivas podem ter levado as crianças mais velhas a sofrerem uma influência mais forte dessas pistas situacionais, pois o grupo etário de 11 a 12 anos foi aquele que, em média, doou mais adesivos, além de ter concentrado a menor proporção de crianças consideradas egoístas (que não doaram nenhum adesivo).

Conforme a literatura na área (Piazza, Bering, \& Ingram, 2011), à medida que a idade avança, habilidades sociocognitivas ajudam as crianças a compreender o universo social à sua volta, o que produz uma tendência de adesão a padrões de comportamento típicos ou desejáveis dentro do seu grupo. Neste caso, haveria a possibilidade de que o pressuposto piagetiano (Piaget, 1932/1994) de que as crianças por volta dos oito anos de idade seriam igualitaristas reflita, na verdade, apenas um discurso que elas aprenderam a repetir porque são estimuladas desde cedo a compartilharem seus bens com os pares.

Todavia, conforme outros estudos apontam (Smith, Blake, \& Harris, 2013) e, na mesma direção do que observou-se aqui, em uma situação real como a que foi usada na presente pesquisa, houve uma tendência gradual das crianças passarem a se comportar de maneira mais altruísta para com os seus pares a partir dos oito anos, mesmo que, em tese, não tivessem que fazê-lo, já que elas haviam ganho o jogo "Sabichão" e conquistado o direito de fazer o que quisessem com o prêmio (adesivos).

O fato das decisões distributivas das crianças que participaram desta pesquisa ter se baseado, sobretudo, no mérito, significa que o valor do esforço pessoal predominou sobre uma decisão baseada no altruísmo e que, portanto, a manipulação produziu os efeitos esperados. Se esta interpretação estiver correta, então seria de se esperar que, nas situações em que o mérito fosse exaltado em detrimento de outras informações, a tendência de as crianças ficarem com todos os adesivos seria maior do que nos outros casos, e foi justamente o que aconteceu: a condição experimental em que os participantes foram levados a crer que tinham tido um desempenho muito melhor que seus parceiros de jogo $(9 \times 2$, neutra) foi justamente a que concentrou o maior percentual de crianças consideradas "egoístas".

Por outro lado, quando a questão do mérito foi atenuada e confrontada com outras variáveis relacionadas ao cuidado pessoal (adversário iria ficar triste), a tendência a manter para si todos os adesivos foi drasticamente diminuída, o que explicaria o menor percentual de crianças egoístas na condição $6 \times 5$, emotiva. Julga-se que esse fenômeno ocorra como decorrência de estilos de socialização utilizados tanto na família como nas escolas e em outras instituições. $\mathrm{Na}$ realidade, vive-se em uma sociedade onde a meritocracia é muito valorizada e as normas de justiça regulam mais as trocas sociais do que outras formas de justiça (a exemplo da justiça igualitária, justiça por necessidade etc).

As análises referentes à empatia vão ao encontro de estudos anteriores que retratam possíveis diferenças relacionadas ao gênero (Sampaio, Camino, \& Roazzi, 2009), em função dos papéis sociais atribuídos a homens e mulheres em nossa sociedade. Aparentemente, essas diferenças já são incorporadas por meninos e meninas ainda na infância, o que os leva a se identificarem em maior ou menor medida com funções sociais relacionadas ao cuidado que, em geral, são vistas como sendo tipicamente femininas. Além disso, estão de acordo com o que propõe a literatura no campo sobre desenvolvimento da empatia ao longo da infância (Hoffman, 2000) e de suas possíveis relações com avanços na cognição, em especial, em relação à capacidade de tomada de perspectiva.

No que se refere às relações entre empatia e comportamento distributivo, os resultados sugerem que a empatia pode ter estado relacionada às decisões distributivas dos participantes do estudo, contribuindo para que eles estivessem mais dispostos a colaborar com a outra criança (adversário do jogo), em decorrência da mobilização afetiva gerada por sentimentos empáticos produzidos na situação. Conforme propõe Hoffman (2000) a empatia pode atuar no julgamento moral, predispondo os indivíduos a ativarem princípios distributivos relacionados à igualdade e cuidado para com os outros, o que poderia ajudar a explicar os resultados aqui observados.

\section{Considerações finais}

Os resultados do presente estudo lançam luzes a respeito do comportamento de partilha durante a infância e suas relações com o desenvolvimento sociocognitivo e afetivo. Os dados apontam para uma habilidade infantil de coordenar diferentes pistas situacionais e utilizá-las para realizar um julgamento distributivo, especialmente quando essas pistas se relacionam ao mérito e ao cuidado. Em resposta aos questionamentos feitos no início deste estudo, considera-se que os dados obtidos sugerem que o mérito pessoal pode guiar decisões distributivas das 
crianças, mas que sua influência pode ser atenuada se o cuidado para com o outro for focado no momento da tomada de decisões.

Neste sentido, compreende-se que a noção de justiça distributiva de crianças pode ser um produto do cômputo de diversas informações disponíveis no momento da tomada de decisão, inclusive das de ordem afetiva, como a empatia, que podem fazer com que, durante a formação de raciocínios sobre justiça distributiva, outras questões (cuidado, por exemplo) sejam consideradas mais relevantes que o próprio mérito/esforço pessoal.

Recomenda-se que estudos futuros retomem a utilização de situações experimentais "reais", como a que foi empregada no presente estudo, tendo em vista sua capacidade de avaliar mais fidedignamente o comportamento distributivo. Isso quando comparada a situações puramente hipotéticas, que avaliam o julgamento em situações que não tem implicações imediatas e diretas para o sujeito, levando-o, em nossa opinião, a sofrer maior influência da desejabilidade social.
Além disso, propõe-se a replicação deste experimento em um contexto no qual os dois jogadores partam de uma condição de simetria, tendo em vista que o delineamento aqui empregado não permitiu isolar completamente os efeitos do mérito sobre o comportamento de partilha de crianças, sendo esta uma das possíveis limitações do presente estudo.

Por fim, considera-se que outra limitação dessa pesquisa refere-se ao fato de não terem sido produzidos dados que permitam aprofundar a compreensão sobre o significado atribuído pelas crianças a suas próprias decisões distributivas. Apesar das inferências produzidas a partir do comportamento real de partilha servirem como importante indicativo dos princípios distributivos subjacentes às decisões tomadas pelas crianças, julgamos que estudos futuros podem se beneficiar da adoção de desenhos de pesquisa que envolvam abordagem quantitativa e também qualitativa, para que outros aspectos do raciocínio distributivo infantil possam ser melhor compreendidos.

\section{Referências}

Batson, C. D., Klein, T. R., Highberger, L., \& Shaw, L. L. (1995). Immorality from Empathy-Induced Altruism: When Compassion and Justice Conflict. Journal of Personality and Social Psychology, 68(6), 1042-1054. https://doi. org/10.1037/0022-3514.68.6.1042

Batson, C. D., Thompson, E., Seuferling, G., Whitney, H., \& Strongman, J. A. (1999). Moral Hypocrisy: appearing moral to oneself without being so. Journal of Personality and Social Psychology, 77(3), 525-537. https://doi. org/10.1037/0022-3514.77.3.525

Batson, C. D., Lishner, D. A., Carpenter, A., Dulin, L., Harjusola-Webb, S., Stocks, E. L., Gale, S., Hassan, O., \& Sampat, B. (2003) "... As you would have them do unto you": imagining yourself in the other's place stimulate moral action? Personality and Social Psychology Bulletin, 29(9), 1190-1201. https://doi.org/10.1177/0146167203254600

Blake, P. R. \& Rand, D. G. (2010). Currency value moderates equity preference among young children. Evolution and Human Behavior, 31, 210-218. https://doi.org/10.1016/j.evolhumbehav.2009.06.012

Blake, P. R. \& McAuliffe, K. (2011). "I had so much it didn’t seem fair”: Eight-year-olds reject two forms of inequity. Cognition, 120, 215-224. https://doi.org/10.1016/j.cognition.2011.04.006

Brasil. (2012). Resolução 466/12 do Conselho Nacional de Saúde (dispõe sobre a ética na pesquisa com seres humanos). Brasília: Ministério da Saúde.

Bryant, B. K. (1982). An index of empathy for children and adolescents. Child development, 53, 413-425. https://doi. org/10.2307/1128984

Conselho Federal de Psicologia. (2000). Resolução 0016/2000 (dispõe sobre a pesquisa em Psicologia com seres humanos). Brasília.

Fehr, E., Bernhard, H., \& Rockenbach, B. (2008). Egalitarianism in young children. Nature, 454, 1079-1083. https:// doi.org/10.1038/nature07155

Hoffman, M. (2000). Empathy and moral development: implications of caring and justice. New York: Cambridge University Press. https://doi.org/10.1017/CBO9780511805851

Piaget, J. (1994). The Moral Judgment of the Child. New York: Free Press (originalmente publicado em 1932).

Piazza, J., Bering, J. M., \& Ingram, G. (2011), "Princess Alice is watching you": Children's belief in an invisible person inhibits cheating. Journal of Experimental Child Psychology, 109, 311-320. https://doi.org/10.1016/j.jecp.2011.02.003

Posid, T., Fazio, A., \& Cordes, S. (2015). Being sticker rich: numerical context influences children's sharing behavior. PLoS ONE, 10(11), 1-18. https://doi.org/10.1371/journal.pone.0138928

Ribeiro, J., Koller, S. H., \& Camino, C. (2002). Adaptação e validação de duas escalas de empatia para uso no Brasil. Estudos de Psicologia (Campinas), 18(3), 43-53. 
Sampaio, L. R., Camino, C., \& Roazzi, A. (2007). Justiça distributiva em crianças de 5 a 10 anos de idade. Psicologia: Reflexão e Crítica, 20 (2), 195-202. https://doi.org/10.1590/S0102-79722007000200004

Sampaio, L., Camino, C. P., \& Roazzi, A. (2009) Justiça distributiva: uma revisão da literatura psicossocial e desenvolvimentista. Psicologia em Estudo, 14(4), 631-640. https://doi.org/10.1590/S1413-73722009000400003

Sampaio, L. R. \& Pires, M. F. D. N. (2015). Sharing in Private and Public Situations: does this really Matter for Children? Spanish Journal of Psychology, 18(42), 1-7. https://doi.org/10.1017/sjp.2015.45

Shaw, A. \& Olson, K.R. (2013). All inequality is not equal: children correct inequalities using resource value. Frontiers in Psychology, 4, 1-9. https://doi.org/10.3389/fpsyg.2013.00393

Smith, C. E., Blake P. R., \& Harris P. L. (2013). I should but I won't: Why young children endorse norms of fair sharing but do not follow them. PloS One, 8, e59510. https://doi.org/10.1371/journal.pone.0059510

Wong, M. M. A. \& Nunes, T. (2003). Hong Kong children's concept of distributive justice. Early Child Development and Care, 173(1), 119-129. https://doi.org/10.1080/0300443022000022477

Nota:

Esta pesquisa recebeu apoio do Conselho Nacional de Desenvolvimento Científico (CNPq),

através da Chamada CNPq/CAPES no 07/2011, processo 400763/2011-7.

Autores:

Leonardo Rodrigues Sampaio - Doutor em Psicologia Cognitiva, Universidade Federal do Vale do São Francisco.

Cleonice Pereira dos Santos Camino - Doutora em Psicologia, Universidade Federal da Paraíba.

Endereco para correspondência:

Leonardo Rodrigues Sampaio

Av. José de Sá Maniçoba, s/n.

Universidade Federal do Vale do São Francisco - UNIVASF

Colegiado de Psicologia

56304-917 - Petrolina, PE, Brasil

<leonardo.sampaio@univasf.edu.br>

Recebido em: 12.11.2016

Aceito em: 27.06.2017 